\title{
Extracorporeal Membrane Oxygenation in Cardiogenic Shock due to Acute Myocardial Infarction: A Systematic Review
}

\author{
Marius Andrei Zavalichi $\mathbb{D}^{1},{ }^{1}$ Ionut Nistor $\mathbb{D}^{2,3}$ Alina-Elena Nedelcu ${ }^{2}{ }^{4}{ }^{4}$ \\ Simona Daniela Zavalichi $\mathbb{D}^{\mathrm{D}}{ }^{4}$ Cătălina Marina Arsenescu Georgescu $\mathbb{D}^{\mathbb{D}}{ }^{1}$ \\ Cristian Stătescu $\mathbb{D}^{1},{ }^{1}$ and Adrian Covic $\mathbb{D}^{2,3}$ \\ ${ }^{1}$ Cardiovascular Diseases Institute "Prof. Dr. George I.M. Georgescu", "Grigore T. Popa” University of Medicine and Pharmacy, \\ Iasi, Romania \\ 2"C. I. Parhon" University Hospital, "Grigore T. Popa” University of Medicine and Pharmacy, Iasi, Romania \\ ${ }^{3}$ Research Methodology and Evidence Based Medicine Center, Iasi, Romania \\ ${ }^{4}$ Rehabilitation Clinical Hospital, "Grigore T. Popa” University of Medicine and Pharmacy, Iasi, Romania
}

Correspondence should be addressed to Ionut Nistor; ionutni@yahoo.com

Received 21 December 2019; Revised 7 April 2020; Accepted 9 April 2020; Published 22 April 2020

Academic Editor: Guiming Liu

Copyright (C) 2020 Marius Andrei Zavalichi et al. This is an open access article distributed under the Creative Commons Attribution License, which permits unrestricted use, distribution, and reproduction in any medium, provided the original work is properly cited.

Background. Cardiogenic shock is associated with high mortality, despite new strategies for reperfusion therapy. Short-term circulatory support devices may provide adequate support for appropriate myocardial and organ perfusion. Objectives. This review is aimed at evaluating the impact on survival when using venoarterial extracorporeal membrane oxygenation ( $\mathrm{V}$-A ECMO) in patients with cardiogenic shock due to acute myocardial infarction (AMI). Methods. We performed a systematic review that included studies using V-A ECMO in patients with cardiogenic shock. Time on ECMO, side effects, and the number of deceased patients, transplanted or upgraded to durable assist devices were analysed. Literature search was done using PubMed/MEDLINE (inception (1969) to January 10, 2019), ProQuest (inception (January 14, 1988) to January 10, 2019), and clinicaltrials.gov (inception (September 12, 2005) to January 10, 2019), by 2 authors. This protocol is registered with PROSPERO (no. CRD42019123982). Results. We included 9 studies with a total of 1,998 adult patients receiving V-A ECMO for AMI-induced cardiogenic shock. Survival rate varied from $30.0 \%$ to $79.2 \%$ at discharge and from $23.2 \%$ to $36.1 \%$ at 12 months. Time on ECMO varied between 1.96 and 6.0 days. Reported serious adverse events were gastrointestinal bleeding (3.6\%) and peripheral complications (8.5\%). Conclusion. The use of V-A ECMO among patients with AMI-induced cardiogenic shock may provide survival benefits. However, V-A ECMO treatment effects are inconclusive because of limitations in cohort design and reporting.

\section{Introduction}

Myocardial infarction accounts for 5-10\% of patients with cardiogenic shock $[1,2]$. Additionally, cardiogenic shock represents the main cause of mortality in patients with acute myocardial infarction (AMI) [3], with the reporting data showing an increased incidence of cardiogenic shock from $6.5 \%$ in 2003 to $10.1 \%$ in 2010 [4].

Establishing blood flow by percutaneous coronary intervention (PCI) and a coronary artery bypass graft (CABG) remain the key approaches for patients with AMI. However, success rate remains low, despite maximum therapy [5].
New strategies for reperfusion therapy have been associated with improvement in survival rates, but significant disparities among trials may be observed [6].

The 2017 European Society of Cardiology Guidelines suggest the use of short-term active mechanical support in cardiogenic shock based on class IIb, level of evidence C [7].

The use of intra-aortic balloon counter pulsation (IABP) among patients with AMI and cardiogenic shock did not reduce early or late mortality, as demonstrated in the IABPSHOCK II trial [8], while ventricular assist devices (VAD) and ECMO are increasingly popular but have not been sufficiently evaluated in clinical trials [7]. 
The extracorporeal membrane oxygenation (ECMO) machine provides support that resembles the cardiopulmonary bypass using a centrifugal pump and a membrane oxygenator with a drainage and return cannula. Venoarterial ECMO provides the benefit of maintaining an optimal cardiac output, before or after coronary revascularization, enabling the use of lower doses of vasoactive drugs. In some studies, it was associated with high survival rates (up to $51 \%$ survival to discharge) in cardiogenic shock, being used as rescue therapy in these patients [9], with short- and long-term survival benefits of cardiopulmonary resuscitation compared to standard care [10].

In addition, the Extracorporeal Life Support Organization guidelines include special algorithms for using ECMO as a bridge-to-recovery approach for postacute myocardial infarction [11].

Other mechanical devices such as Impella are used after ECMO commencement, to assure optimal haemodynamic conditions and reducing time on ECMO, playing a key role in cardiogenic shock [12].

Recent trials suggest the combination of $\mathrm{V}$-A ECMO and the Impella device in the so-called ECPELLA strategy, providing more benefits than $\mathrm{V}-\mathrm{A}$ ECMO with surgical venting, in order to avoid increased left ventricular afterload during extracorporeal support [13].

Despite such premises, survival benefits of ECMO therapy for cardiogenic shock are not consistent, covering a wide range of percentages that reflect a great variability of potential advantages versus disadvantages of this type of mechanical support [14].

This review is aimed at evaluating the impact on survival, potential benefits, and side effects of V-A ECMO in patients with cardiogenic shock after myocardial infarction (ST-segment elevation myocardial infarction and non-ST segment elevation myocardial infarction) in a systematic way.

\section{Materials and Methods}

\subsection{Methods}

2.1.1. Protocol and Registration. This protocol has been registered in the PROSPERO database of systematic review protocols, under registration number CRD42019123982.

2.1.2. Data Sources/Search Strategy. We have searched PubMed/MEDLINE (inception (1969) to January 10, 2019), ProQuest (inception (January 14, 1988) to January 10, 2019), and clinicaltrials.gov (inception (September 12, 2005) to January 10, 2019) without language restrictions. Hand searching for relevant articles was done on reference lists from textbooks, articles, and scientific proceedings. The search terms used and a detailed search strategy are shown in Table 1.

2.1.3. Study Selection. We have searched for observational studies and randomized clinical trials for adults with myocardial infarction complicated by cardiogenic shock that were treated with ECMO for mechanical circulatory support and have reported data about the impact of V-A ECMO on survival, ECMO duration, complications associated with the use of ECMO (limb ischaemia, encephalopathy, acute kidney
TABLE 1: Keywords used for search strategy.

\begin{tabular}{l}
\hline Keywords \\
\hline Extracorporeal membrane oxygenation \\
ECMO \\
Veno-arterial extracorporeal membrane oxygenation \\
Veno-arterial ECMO \\
V-A ECMO \\
Mechanical circulatory support \\
Extracorporeal life support \\
ECLS \\
Cardiogenic shock \\
CS \\
Acute myocardial infarction \\
AMI \\
${ }^{*}$ ECLS: extracorporeal life support; CS: cardiogenic shock; AMI: acute \\
myocardial infarction.
\end{tabular}

injury, infections, and bleeding), and the opportunity to switch to ventricular assist devices.

Studies that reported data for more than 10 patients were only included.

2.1.4. Data Extraction and Synthesis. Data extraction was done independently by 2 authors (MZ and AN) using standardized data extraction forms. When more than one publication of a study was found, only the publication with the most complete data was included. Extracted data included identifiable information, study outcomes, details of the study protocol, and demographic data. We extracted the characteristics of each study, including type of ECMO; ECMO duration; survival rate at 1,6, and 12 months; and if ECMO was used as a bridge to transplantation. Disagreements were resolved by consultation between all authors. Methods used were similar to the methods of Bilha et al. [15].

2.1.5. Risk of Bias. Quality of the selected studies was independently evaluated by 2 reviewers ( $\mathrm{MZ}$ and $\mathrm{AN}$ ), using the Newcastle-Ottawa scale (NOS); according to the NOS, 3 methodological categories were used for assessment: selection (score $0-4$ ), comparability (score $0-2$ ), and outcome (score 0-3). Quality was considered high if the score was 79 , intermediate if the score was $4-6$, and low if the score was $0-3$.

Disagreements were resolved by consensus [16].

2.2. Statistical Analysis. We performed a narrative synthesis using data extraction tables, independently carried out by 2 authors.

\section{Results}

For study selection, a flow diagram providing the selection process of the included studies is shown in Figure 1.

The initial search resulted in 2,302 potentially relevant articles. A thorough analysis of the abstracts led to the exclusion of 219 articles referring to several population categories that were of no interest for this review (children, pregnant 


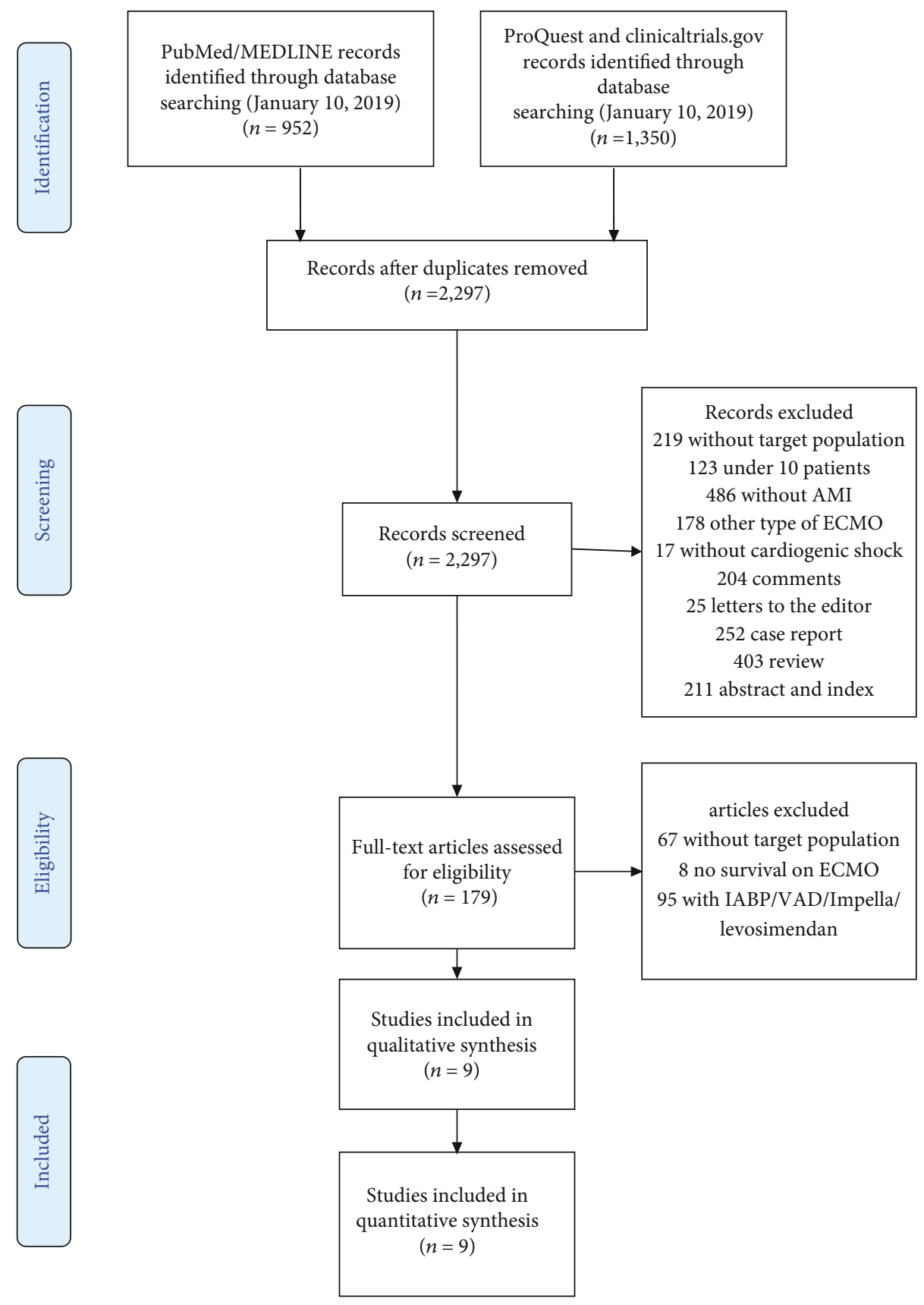

FIGURE 1: Selection process of the included studies.

women, and animal subjects); 681 articles were excluded because the outcomes were not reported (myocardial infarction/cardiogenic shock/V-A ECMO); 123 reported studies under 10 patients for analysis, as well as other case reports, editorials, and reviews $(n=1,095)$, were not included. Finally, 5 duplicates were also excluded.

A total of 179 full-text articles were thoroughly analysed; 8 of these were excluded due to absence of survival data, 67 did not include the target population, 95 were excluded because they reported data about the use of intraaortic balloon counter-pulsation/percutaneous ventricular assist device prior to ECMO. After an in-depth analysis, 9 observational studies involving 1,998 patients were included in this systematic review.

3.1. Baseline Study and Patient Characteristics. The main characteristics of the included studies are presented in Table 2 .

Median follow-up period generally varied between 1 and 12 months; 3 studies in the People's Republic of China, 2 in Taiwan, 1 in Germany, 2 in the United States of America, and 1 in South Korea were performed. The mean age of the patients involved varied between 55 and 65 years; males accounted for $76.02 \%$ of the total number of patients. 
TABLE 2: Baseline and patient characteristics.

\begin{tabular}{|c|c|c|c|c|c|c|}
\hline Study & ECMO duration & $\begin{array}{c}\text { Survive-to- } \\
\text { discharge } \\
\text { (no. of patients) }\end{array}$ & $\begin{array}{l}\text { Survival rate at } \\
1 \text { month, } 6 \text { months, } \\
\text { and } 12 \text { months }\end{array}$ & ECMO complications & Transplant & $\begin{array}{l}\text { Assist } \\
\text { device }\end{array}$ \\
\hline Negi et al. [17] & NA & $9(58 \%)$ & $\begin{array}{l}58 \% 1 \text { month } \\
\text { NA } 6 \text { months } \\
\text { NA } 12 \text { months }\end{array}$ & NA & NA & NA \\
\hline Chang et al. [18] & 1.96 days & $576(33.8 \%)$ & $\begin{array}{l}34 \% 1 \text { month } \\
\text { NA } 6 \text { months } 23.2 \% \\
12 \text { months }\end{array}$ & $\begin{array}{c}\text { Acute renal failure } n=393 \\
\text { Gastrointestinal } \\
\text { bleeding } n=63 \\
\text { Intracerebral } \\
\text { haemorrhage } n=29 \\
\text { Ischaemic stroke } n=49\end{array}$ & NA & NA \\
\hline Wu et al. [19] & $\begin{array}{c}66 \mathrm{~h} \text { for PCI } \\
(2-259) \\
100 \mathrm{~h} \text { for CABG } \\
(43-504)\end{array}$ & $14(40 \%)$ & $\begin{array}{c}\text { NA } 1 \text { month } \\
84 \% 6 \text { months } \\
\text { (of survivors) } 73 \% \\
12 \text { months (of survivors) }\end{array}$ & $\begin{array}{c}\text { Limb ischaemia } n=3 \\
\text { Major anoxic } \\
\text { encephalopathy } n=16 \\
\text { Acute renal failure } n=16\end{array}$ & 1 & 0 \\
\hline Chou et al. [20] & NA & $15(34.9 \%)$ & $\begin{array}{l}\text { NA } 1 \text { month } \\
\text { NA } 6 \text { months } \\
34.9 \% \\
12 \text { months }\end{array}$ & $\begin{array}{c}\text { MOF } n=21 \\
\text { Sepsis } n=5 \\
\text { Other (ischaemic bowel } \\
\text { disease, brain death) } n=2\end{array}$ & NA & NA \\
\hline Huang et al. [21] & $102.3 \pm 66.6 \mathrm{~h}$ & $6(30 \%)$ & $\begin{array}{l}\text { NA } 1 \text { month } \\
\text { NA } 6 \text { months } \\
\text { NA } 12 \text { months }\end{array}$ & $\begin{array}{c}\text { Septic shock } n=1 \\
\text { MOF } n=1 \\
\text { Hypoxic ischaemic } \\
\text { encephalopathy } n=15 \\
\text { Coagulation } \\
\text { dysfunction } n=12\end{array}$ & NA & NA \\
\hline Sandoval Y et al. [22] & 6 (4-7) days & $19(79.16 \%)$ & $\begin{array}{l}79.16 \% 1 \text { month } \\
\text { NA } 6 \text { months } \\
\text { NA } 12 \text { months }\end{array}$ & NA & 0 & 4 \\
\hline Guenther et al. [23] & $120 \pm 81 \mathrm{~h}$ & NA & $\begin{array}{l}52 \% 1 \text { month } \\
\text { NA } 6 \text { months } \\
\text { NA } 12 \text { months }\end{array}$ & $\begin{array}{c}\text { MOF } n=9 \\
\text { Diffuse } \\
\text { encephalopathy } n=1 \\
\text { Intermittent } \\
\text { haemodialysis } n=1\end{array}$ & 1 & 4 \\
\hline Jeon et al. [24] & NA & $43(39.8 \%)$ & $\begin{array}{c}39.8 \% 1 \text { month } \\
37 \% 6 \text { months } \\
36.1 \% \\
12 \text { months }\end{array}$ & NA & NA & NA \\
\hline Fu et al. [26] & NA & $12(44 \%)$ & $\begin{array}{l}\text { NA } 1 \text { month } \\
\text { NA } 6 \text { months } \\
\text { NA } 12 \text { months }\end{array}$ & NA & NA & NA \\
\hline
\end{tabular}

*h: hours; CABG: coronary artery bypass graft; MOF: multiple organ failure.

The most frequent comorbidities were diabetes mellitus and stroke. Negi et al. [17] have reported that $56.2 \%$ of the patients had diabetes. Stroke rates were similar, varying from $10.9 \%$ [18] to $14.2 \%$ [19]. Hypertension was present in 55.8\% of the population included in the study by Chou et al. [20], in $46.6 \%$ of the patients by Chang et al. [18], and $45 \%$ by Huang et al. [21]. Several studies reported a history of previous heart disease [18-20,22]. The comorbidities present in ECMO patients are summarized in Table 3.

3.2. ECMO Duration. ECMO duration varied: 1.96 days in Chang et al. [18], 2.75 days in $\mathrm{Wu}$ et al. [19], 5.0 days in Guenther et al. [23], 4.26 days in Huang et al. [21], and 6 days in Sandoval et al. [22] studies.

\subsection{Survival on ECMO}

3.3.1. Survival Rate after Weaning from ECMO. Only 3 studies have reported the total number of patients weaned from ECMO and the number of those who did not survive to discharge after being weaned off [21-23]. The data is summarized in Table 4.

\subsection{Study Outcomes}

3.4.1. V-A ECMO Survival at Discharge at 1, 6, and 12 Months. Overall, survival at discharge was reported in 8 out of the 9 studies included, with the highest rate registered by Sandoval et al. [22] (79.16\%). Despite this survival rate, the 


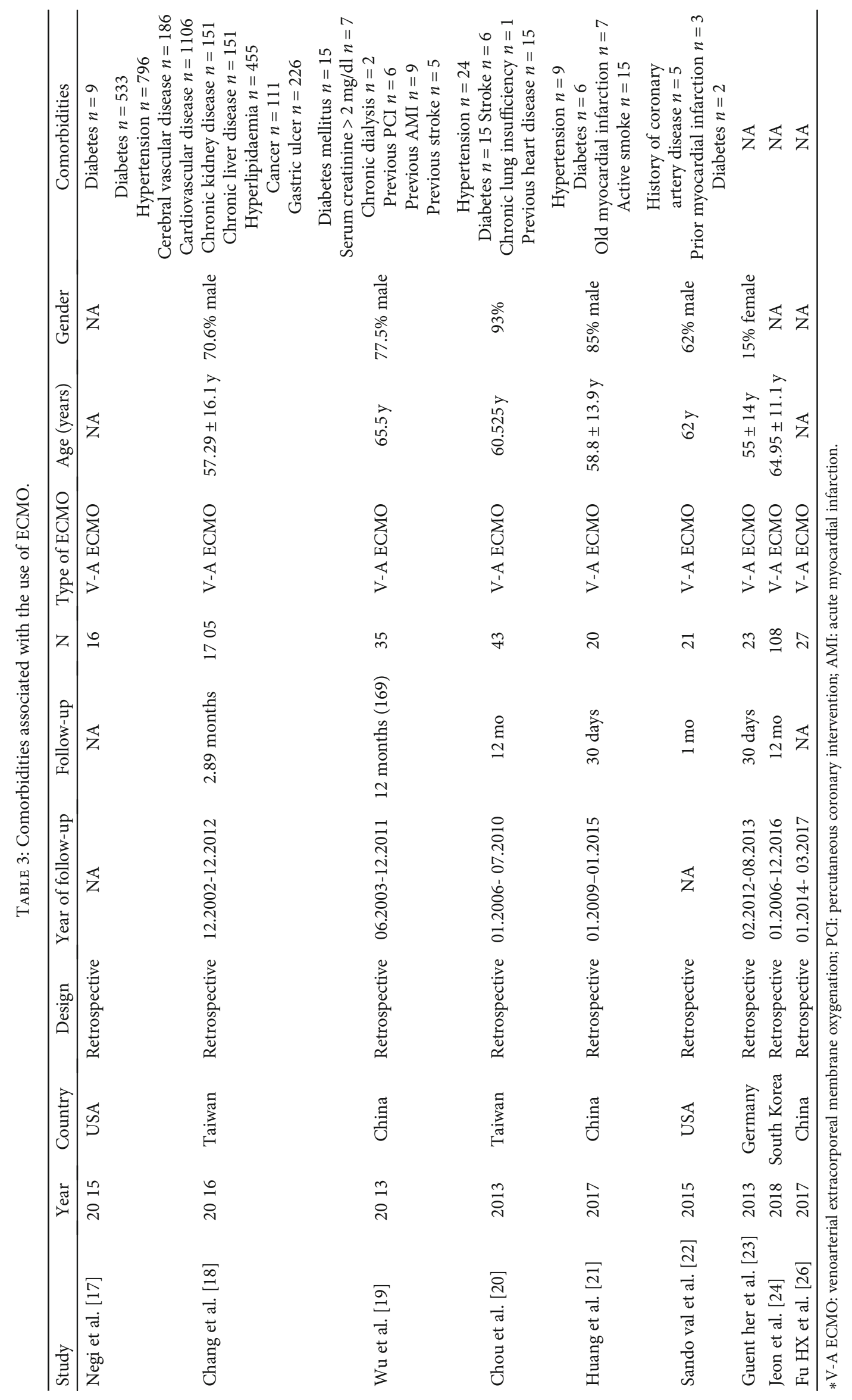


TABle 4: Patients weaned from ECMO.

\begin{tabular}{lcc}
\hline Study & $\begin{array}{c}\text { Number of patients } \\
\text { weaned from V-A ECMO }\end{array}$ & $\begin{array}{c}\text { Number of } \\
\text { nonsurvivors } \\
\text { after weaning }\end{array}$ \\
\hline Negi et al. [17] & NA & NA \\
Chang et al. [18] & NA & NA \\
Wu et al. [19] & 22 & NA \\
Chou et al. [20] & 15 & NA \\
Huang et al. [21] & 8 & 2 \\
Sandoval et al. [22] & 16 & 5 \\
Guenther et al. [23] & 15 & 3 \\
Jeon et al. [24] & NA & NA \\
Fu et al. [26] & NA & NA \\
\hline
\end{tabular}

TABLE 5: Most frequent complications associated with the use of ECMO.

\begin{tabular}{lcc}
\hline Outcome & Number of studies & Number of events \\
\hline Limb ischaemia & 1 & 3 \\
Encephalopathy & 3 & 32 \\
Ischaemic stroke & 1 & 49 \\
Intracerebral & 1 & 29 \\
haemorrhage & 1 & 63 \\
Gastrointestinal bleeding & 3 & 410 \\
Acute renal failure & 3 & 31 \\
MOF & 2 & 6 \\
Sepsis &
\end{tabular}

${ }^{*}$ MOF: multiple organ failure.

number of patients included was low, with only 21 subjects and no follow-up data being available. Survival at 1 month after extracorporeal life support was 34\%, reported by Chang et al. [18], 52\% by Guenther et al. [23], 39.8\% by Jeon et al. [24], and $58 \%$ by Negi et al. [17].

Survival at 6 months ranged from $33.6 \%$ in Wu et al. [19] to $37 \%$ in Jeon $\mathrm{KH}$ et al. [24].

Survival at 12 months was reported at $73 \%$ in $\mathrm{Wu}$ et al. [19], 23.2\% in Chang et al. [18], 34.9\% in Chou et al. [20], and $36.1 \%$ in Jeon et al. [24].

3.4.2. Complications during Hospitalization of Patients with Cardiogenic Shock on ECMO Support. The most common adverse effect was acute kidney failure, seen in $45.7 \%$ in $\mathrm{Wu}$ et al. [19] (25.7\% were patients with chronic kidney disease), $23 \%$ in Chang et al. [18] (8.8\% already had chronic kidney disease), and $58.3 \%$ in a subgroup of Sattler et al. [25].

However, only these 3 studies reported data for acute kidney injury.

Considering peripheral complications, limb ischaemia was encountered in $8.5 \%$ of the study population [19].

In terms of cerebral complications, hypoxic ischaemic encephalopathy was the most common (75\% in Huang et al. [21], 45.7\% in Wu et al. [19]). Furthermore, ischaemic stroke and intracerebral haemorrhage were also found (2.8\% and $1.7 \%$, respectively, in Chang et al. [18]).
Gastrointestinal bleeding was reported by Chang et al. [18] in 63 patients, representing 3.6\% (13.2\% with previous gastric ulcer disease and $6.5 \%$ with cancer) of the study population.

Sepsis was found in $11.6 \%$ of patients by Chou et al. [20], with only 1 case of septic shock in Huang et al. [21]. Multiple organ failure was encountered in $48.8 \%$ in Chou et al. [20] and $39.1 \%$ in Guenther et al. [23] studies.

Data related to complications associated with the use of ECMO were not reported in 4 studies $[17,22,24,26]$. The most frequent complications reported are summarized in Tables 2 and 5 .

\subsubsection{Opportunity to Switch to Ventricular Assist Devices: Subgroup Analysis Transplantation and Assistive Devices}

(1) Heart Transplantation. A total of 2 out of 1,998 patients included in this review were eligible to receive a heart transplant, after weaning from ECMO $[19,23]$.

(2) Assistive Devices. The usage rate of assistive devices was low, being reported by 2 studies. In the study conducted by Guenther et al. [23], 2 patients underwent biventricular assist device implantation (Berlin Heart $\mathrm{EXCOR}^{\circledR}$ ) and 2 left ventricular assist device implantations (HeartWare ${ }^{\circledR}$ ); 4 out of 24 patients (16.6\%) enrolled in the study conducted by Sandoval et al. [22] were further placed on left ventricular assist devices.

(3) Study Quality. Quality score of the included studies ranged from 5 to 9 , with a mean quality score of 7 . This corresponds to a medium-to-high quality of the included studies. The detailed scores are provided in Table 6.

\section{Discussion}

4.1. Summary of Findings. This systematic review shows a great variability in survival rates for patients treated with ECMO. We have included 9 studies with 1,998 patients and showed that the use of ECMO might prove a useful tool to increase the survival rate in patients with cardiogenic shock due to myocardial infarction (which is less than $50 \%$ with only standard care [27]) (with rates varying from $30.0 \%$ to $76.2 \%)$. These highly heterogeneous data was partly due to the nature of observational studies included, with diverse populations. In fact, these rates are similar to the ones reported by the Extracorporeal Life Support Organization in 2017 with a survival-to-discharge rate of $41 \%$, using V-A ECMO devices [28].

According to the 2017 European Society of Cardiology Guidelines for the management of acute myocardial infarction in patients presenting with ST-segment elevation, short-term mechanical circulatory support (ECMO) may be considered for patients with refractory shock (class IIb, level C). [7].

The use of ECMO in critical cases increased from 1.06 to 1.77 cases per 100,000 patients by 2014 in the USA and from 1.1 cases in 2007 to 6.2 cases in 2014 in Germany [29]. 
TABLE 6: Newcastle-Ottawa scale for assessment of quality of included studies (each asterisk represents if individual criterion within the subsection was fulfilled).

\begin{tabular}{|c|c|c|c|c|c|c|c|c|c|c|}
\hline $\begin{array}{l}\text { Quality assessment } \\
\text { Criteria }\end{array}$ & Acceptable $\left(^{*}\right)$ & $\begin{array}{l}\mathrm{Wu} \\
\text { et al. }\end{array}$ & $\begin{array}{l}\text { Chang } \\
\text { et al. }\end{array}$ & $\begin{array}{l}\text { Guenther } \\
\text { et al. }\end{array}$ & $\begin{array}{l}\mathrm{Fu} \\
\text { et al. }\end{array}$ & $\begin{array}{l}\text { Huang } \\
\text { et al. }\end{array}$ & $\begin{array}{l}\text { Chou } \\
\text { et al. }\end{array}$ & $\begin{array}{l}\text { Sandoval } \\
\text { et al. }\end{array}$ & $\begin{array}{l}\text { Jeon } \\
\text { et al. }\end{array}$ & $\begin{array}{l}\text { Negi } \\
\text { et al. }\end{array}$ \\
\hline $\begin{array}{l}\text { (1) Representativeness of } \\
\text { the exposed cohort }\end{array}$ & $\begin{array}{l}\text { Representative of } \\
\text { average adult in } \\
\text { community } \\
\text { (age/sex/being at } \\
\text { risk of disease) }\end{array}$ & * & * & * & * & * & * & * & * & * \\
\hline $\begin{array}{l}\text { (2) Selection of the nonexposed } \\
\text { cohort }\end{array}$ & $\begin{array}{l}\text { Drawn from the } \\
\text { same community as } \\
\text { the exposed cohort }\end{array}$ & * & * & - & - & - & * & - & - & - \\
\hline (3) Ascertainment of exposure & $\begin{array}{l}\text { Secure record, } \\
\text { structured } \\
\text { interview }\end{array}$ & * & * & * & * & * & * & * & * & * \\
\hline $\begin{array}{l}\text { (4) Demonstration that outcome } \\
\text { of interest was not present at } \\
\text { the start of the study }\end{array}$ & & * & * & * & * & * & * & * & * & * \\
\hline $\begin{array}{l}\text { (5) Adequate control for the } \\
\text { most important confounder? }\end{array}$ & & * & * & * & - & * & - & $*$ & - & * \\
\hline $\begin{array}{l}\text { (6) Adequate control for any } \\
\text { additional factor? }\end{array}$ & & * & * & * & - & * & * & - & - & - \\
\hline (7) Assessment of outcome & $\begin{array}{l}\text { Independent or } \\
\text { blind assessment }\end{array}$ & * & * & * & * & * & * & * & * & * \\
\hline $\begin{array}{l}\text { (8) Was follow-up long enough } \\
\text { for outcomes to occur? }\end{array}$ & & * & * & * & * & - & * & * & * & * \\
\hline $\begin{array}{l}\text { (9) Adequacy of follow-up of } \\
\text { cohorts }\end{array}$ & $\begin{array}{l}\text { Complete follow-up, } \\
\text { or subjects lost to } \\
\text { follow-up unlikely } \\
\text { to introduce bias }\end{array}$ & * & * & * & - & - & * & * & * & * \\
\hline Overall quality score $($ maximum $=9)$ & & 9 & 9 & 8 & 5 & 6 & 8 & 7 & 6 & 7 \\
\hline
\end{tabular}

A crucial aspect that may improve future success is immediate use by multidisciplinary teams specialising in ECMO, facilitating the safest transportation to PCI/CABG centres. A prognostic tool for predicting survival may be the SAVE score created by Schmidt et al. [30], included in the 2016 European Society of Cardiology Guidelines for the Diagnosis and Treatment of Acute and Chronic Heart Failure [31].

Constant upgrade to durable solutions such as ventricular assist devices that ensure a bridge-to-survival or transplantation could become the cornerstone of modern cardiology. Extracorporeal life support followed by ventricular assist devices increases the chance of receiving a heart transplant, by gaining time to find the right donor [32].

Among patients with AMI-induced cardiogenic shock, the usage of $\mathrm{V}$-A ECMO may provide benefits in terms of survival. However, treatment effects of V-A ECMO are inconclusive due to limitations in cohort methods and reporting [7].

In our opinion, complications such as multiple organ failure, cerebral complications, and kidney failure may be related to cardiogenic shock, rather than to the use of ECMO.

ECMO was mostly associated with acute kidney failure (with a high percentage of patients having previous renal impairment), being a common complication, as it is shown in a systematic review that included 46 studies performed in patients treated with ECMO, where the occurrence rate was $52 \%$ [33].

In our study, rates varied between $24 \%$ and $47 \%$, a complication that may be prevented by reducing the time to insertion of V-A ECMO. Additionally, ECMO infection prevention may be achieved by performing an accurate procedure. Nonetheless, vascular complications such as haemorrhage and limb ischaemia, seen in $8.5 \%$ of the included patients in our study, had similar rates, as reported in the literature.

\section{Conclusions}

Our study has its limitations and strengths. We performed a systematic literature search and a detailed survival analysis. However, our study could only identify observational studies. Additionally, sample size was relatively small, and data were not fully reported.

We could not exclude publication bias of original studies, as authors who did not register positive results on ECMO, or did not find any effect at all, were less likely to publish their results.

V-A ECMO for patients with acute myocardial infarction-induced cardiogenic shock represents a temporary support that provides benefits compared to standards of care, being an upgradable device for advanced life support that could assure a higher survival rate. 


\section{Data Availability}

The data supporting this Systematic review are from previously reported studies and datasets, which have been cited. The processed data are available from the corresponding author upon request.

\section{Conflicts of Interest}

The authors declare that they have no conflicts of interest.

\section{References}

[1] R. J. Goldberg, N. A. Samad, J. Yarzebski, J. Gurwitz, C. Bigelow, and J. M. Gore, "Temporal trends in cardiogenic shock complicating acute myocardial infarction," New England Journal of Medicine, vol. 340, no. 15, pp. 1162-1168, 1999.

[2] R. J. Goldberg, J. M. Gore, C. A. Thompson, and J. H. Gurwitz, "Recent magnitude of and temporal trends (1994-1997) in the incidence and hospital death rates of cardiogenic shock complicating acute myocardial infarction: the second national registry of myocardial infarction," American Heart Journal, vol. 141, no. 1, pp. 65-72, 2001

[3] M. Noc and P. Radsel, "Urgent invasive coronary strategy in patients with sudden cardiac arrest," Current Opinion in Critical Care, vol. 14, no. 3, pp. 287-291, 2008.

[4] D. Kolte, S. Khera, W. S. Aronow et al., "Trends in incidence, management, and outcomes of cardiogenic shock complicating ST-elevation myocardial infarction in the United States," Journal of the American Heart, vol. 3, no. 1, article e000590, 2014.

[5] L. Khalid and S. H. Dhakam, "A review of cardiogenic shock in acute myocardial infarction," Current Cardiology Reviews, vol. 4, no. 1, pp. 34-40, 2008.

[6] S. van Diepen, J. N. Katz, N. M. Albert et al., "Contemporary management of cardiogenic shock: a scientific statement from the American Heart Association," Circulation, vol. 136, no. 16, pp. e232-e268, 2017.

[7] B. Ibanez, S. James, S. Agewall et al., "2017 ESC guidelines for the management of acute myocardial infarction in patients presenting with ST-segment elevation: the task force for the management of acute myocardial infarction in patients presenting with ST-segment elevation of the European Society of Cardiology (ESC)," European Heart Journal, vol. 39, no. 2, pp. 119-177, 2018.

[8] H. Thiele, U. Zeymer, F. J. Neumann et al., "Intraaortic balloon support for myocardial infarction with cardiogenic shock," New England Journal of Medicine, vol. 367, no. 14, pp. 12871296, 2012.

[9] R. El Sibai, R. Bachir, and M. El Sayed, "ECMO use and mortality in adult patients with cardiogenic shock: a retrospective observational study in U.S. hospitals," BMC Emergency Medicine, vol. 18, no. 1, 2018.

[10] Y.-S. Chen, J.-W. Lin, H.-Y. Yu et al., "Cardiopulmonary resuscitation with assisted extracorporeal life-support versus conventional cardiopulmonary resuscitation in adults with in-hospital cardiac arrest: an observational study and propensity analysis," The Lancet, vol. 372, no. 9638, pp. 554-561, 2008.

[11] ELSO, Guidelines for Cardiopulmonary Extracorporeal Life Support Extracorporeal Life Support Organization, 2017.
[12] M. P. Flaherty, A. R. Khan, and W. W. O'Neill, "Early initiation of Impella in acute myocardial infarction complicated by cardiogenic shock improves survival: a meta-analysis," JACC. Cardiovascular Interventions, vol. 10, no. 17, pp. 18051806, 2017.

[13] S. M. Patel, J. Lipinski, S. G. Al-Kindi et al., "Simultaneous venoarterial extracorporeal membrane oxygenation and percutaneous left ventricular decompression therapy with Impella is associated with improved outcomes in refractory cardiogenic shock," ASAIO Journal, vol. 65, no. 1, pp. 21-28, 2019.

[14] P. Meani, M. Matteucci, F. Jiritano et al., "Long-term survival and major outcomes in post-cardiotomy extracorporeal membrane oxygenation for adult patients in cardiogenic shock," Annals of Cardiothoracic Surgery, vol. 8, no. 1, pp. 116-122, 2019.

[15] S. C. Bilha, I. Nistor, A. Nedelcu et al., "The effects of bariatric surgery on renal outcomes: a systematic review and meta-analysis," Obesity Surgery, vol. 28, no. 12, pp. 3815-3833, 2018.

[16] A. Stang, "Critical evaluation of the Newcastle-Ottawa scale for the assessment of the quality of nonrandomized studies in meta-analyses," European Journal of Epidemiology, vol. 25, no. 9, pp. 603-605, 2010.

[17] S. I. Negi, M. Malahfji, M. Sokolovic et al., "TCT-199 a comparative analysis of use of extracorporeal membrane oxygenation and peripheral ventricular assist device TandemHeart in acute myocardial infarction," Journal of the American College of Cardiology, vol. 66, no. 15, article S073510971505175X, pp. B75-B76, 2015.

[18] C. H. Chang, H. C. Chen, J. L. Caffrey et al., "Survival analysis after extracorporeal membrane oxygenation in critically ill adults: a nationwide cohort study," Circulation, vol. 133, no. 24, pp. 2423-2433, 2016.

[19] M. Y. Wu, Y. H. Tseng, Y. S. Chang, F. C. Tsai, and P. J. Lin, "Using extracorporeal membrane oxygenation to rescue acute myocardial infarction with cardiopulmonary collapse: the impact of early coronary revascularization," Resuscitation, vol. 84, no. 87, pp. 940-945, 2013.

[20] T. H. Chou, C. C. Fang, Z. S. Yen et al., "An observational study of extracorporeal CPR for in-hospital cardiac arrest secondary to myocardial infarction," Emergency Medicine Journal, vol. 31, no. 6, pp. 441-447, 2014.

[21] L. Huang, T. Li, X. M. Hu et al., "External validation of survival predicting models for acute myocardial infarction with extracorporeal cardiopulmonary resuscitation in a Chinese single-center cohort," Medical Science Monitor, vol. 23, pp. 4847-4854, 2017.

[22] Y. Sandoval, K. Anderson, I. Chavez, R. Garberich, D. Hildebrandt, and K. Hryniewicz, "Percutaneous venoarterial extracorporeal membrane oxygenation for patients presenting with refractory cardiogenic shock due to St-segment elevation myocardial infarction," Journal of the American College of Cardiology, vol. 65, no. 10, article S073510971561806X, p. A1806, 2015.

[23] S. Guenther, H. D. Theiss, M. Fischer et al., "Percutaneous extracorporeal life support for patients in therapy refractory cardiogenic shock: initial results of an interdisciplinary team," Interactive Cardiovascular and Thoracic Surgery, vol. 18, no. 3, pp. 283-291, 2014.

[24] K.-H. Jeon, P. S. Song, M.-J. Kim et al., "Prognostic factors of extracorporeal membrane oxygenator therapy for refractory cardiogenic shock or cardiac arrest in acute myocardial 
infarction," Journal of the American College of Cardiology, vol. 71, no. 11, article A1303, 2018.

[25] S. Sattler, N. Khaladj, M.-M. Zaruba et al., "Extracorporal life support (ECLS) in acute ischaemic cardiogenic shock," International Journal of Clinical Practice, vol. 68, no. 4, pp. 529-531, 2014.

[26] H. X. Fu, J. F. Ma, M. F. Hu, Z. N. Zhao, Y. Wang, and L. Miao, "Outcome determinants in cardiac arrest patients secondary to acute myocardial infarction receiving extra-corporeal membrane oxygenation combined with percutaneous coronary intervention therapy," Zhonghua Xin Xue Guan Bing Za Zhi, vol. 45, no. 10, pp. 867-873, 2017.

[27] R. Asleh and J. R. Resar, "Utilization of percutaneous mechanical circulatory support devices in cardiogenic shock complicating acute myocardial infarction and high-risk percutaneous coronary interventions," Journal of clinical medicine, vol. 8, no. 8, p. 1209, 2019.

[28] ECLS Registry ReportInternational Summary, January 2017.

[29] M. J. Stentz, M. E. Kelley, C. S. Jabaley et al., "Trends in extracorporeal membrane oxygenation growth in the United States, 2011-2014," ASAIO Journal, vol. 65, no. 7, pp. 712-717, 2019.

[30] M. Schmidt, A. Burrell, L. Roberts et al., "Predicting survival after ECMO for refractory cardiogenic shock: the survival after venoarterial-ECMO (SAVE)-score," European Heart Journal, vol. 36, no. 33, pp. 2246-2256, 2015.

[31] P. Ponikowski, A. A. Voors, S. D. Anker et al., "2016 ESC guidelines for the diagnosis and treatment of acute and chronic heart failure: The task force for the diagnosis and treatment of acute and chronic heart failure of the European Society of Cardiology (ESC)Developed with the special contribution of the Heart Failure Association (HFA) of the ESC," European Heart Journal, vol. 37, no. 27, pp. 2129-2200, 2016.

[32] A. Guha, B. Hannawi, A. S. Cruz-Solbes et al., "Implication of ventricular assist devices in extracorporeal membranous oxygenation patients listed for heart transplantation," Journal of Clinical Medicine, vol. 8, no. 5, article jcm8050572, p. 572, 2019.

[33] A. J. C. Burrell, V. Bennett, A. L. Serra et al., "Venoarterial extracorporeal membrane oxygenation: a systematic review of selection criteria, outcome measures and definitions of complications," Journal of Critical Care, vol. 53, pp. 32-37, 2019. 